\title{
Dirceu: a potência da composição performativa e suas micropolíticas
}

\section{Dirceu: the power of performative composition and its micropolitics}

\author{
Hildegarda Sampaio \\ Mestranda em Dança pela Universidade Federal da Bahia (UFBA) - hildegarda.sampaio@gmail.com - \\ orcid.org/0000-0003-4684-5028 \\ Lúcia Helena Alfredi de Matos \\ Doutora em Artes Cênicas pela Universidade Federal da Bahia (UFBA). Professora da Universidade Federal da \\ Bahia (UFBA) - luciamatos2@gmail.com - orcid.org/0000-0001-9760-9231
}

\begin{abstract}
Resumo
Aborda as micropolíticas produzidas pelo Núcleo do Dirceu nas composições estabelecidas com a comunidade do bairro Dirceu, em Teresina, durante o processo de criação da obra 1000 Casas, no período de 2011 a 2012. O percurso cartográfico desta escrita aborda aspectos dos dispositivos presentes nas interações e experiências dos sujeitos envolvidos na performance. Para tanto, discute a precariedade e performance à luz de autores como Lígia Clark, Eleonora Fabião e Jacques Rancière, considerando questões e tensões do fazer político nas relações entre arte e vida, público e privado.
\end{abstract}

Palavras-chave: Núcleo do Dirceu. Performance. Micropolítica.

\begin{abstract}
Approaches the micropolitics produced by Núcleo do Dirceu in the compositions were established with the community of Dirceu neighborhood, in Teresina, during the process of creating the piece "1000 Casas" (1000 Houses), from 2011 to 2012. The cartographic course of this written piece addresses aspects of the devices that were present in the interactions and the experiences of the subjects involved in the performance. In order to do this, this paper discusses precariousness and performance. Making use of authors like Lígia Clark, Eleonora Fabião and Jacques Rancière, all the analysis is done while concerning issues and tensions of political doing in the relations between art and life, public and private.
\end{abstract}

Keywords: Núcleo do Dirceu. Performance. Micropolitics.

Recebido em: 26/05/2019

Aceito em: 07/10/2019 


\section{INTRODUÇÃO}

Deslocar entendimentos pode vir a ser uma mudança em eixos considerados como hegemônicos, e/ou uma possibilidade de pôr-se em movimento e/ou, quem sabe, um encontro com novas ideias. Apresentar um exemplo desse deslocamento é o convite aqui feito e será conduzido pelas reflexões sobre como a experiência de um coletivo de artistas conseguiu criar um novo contexto artístico, movendo, friccionando, discutindo arte contemporânea, a partir das ideias de descentralização, articulação política e território. Aqui é delineado um percurso cartográfico que se propõe a aproximações, um deixar levar-se pelas possibilidades de um encontro. O próximo passo é seu, leitor; nosso destino, o bairro Dirceu.

\section{DIRCEU: UM CONTEXTO DAS POSSIBLIDADES}

Visualize o cenário de um Brasil continental; desloque-se para o Nordeste, região ainda considerada a mais vulnerável em relação aos dados sociais e econômicos do país (IBGE, 2017). Nessa busca de foco, direcione-se mais a norte, num estado cercado por espaços fronteiriços com outros cinco estados, cujo nome, de origem tupi-guarani, remete à existência de um rio cheio de piaus: o Piauí, que tem cravado, em seu Parque Nacional da Capivara, os vestígios da presença humana de mais de 50.000 anos. Sua capital, Teresina, é a única capital do Nordeste localizada no interior do estado e não recebe as brisas do Oceano Atlântico. É para essa cidade diversa composta de floresta, cerrado e uma urbanização desordenada, com mais de $70 \%$ da população declarada como parda ou preta (IBGE, 2017), com um calor abafado, intercalado com períodos de chuvas e trovoadas - que convergimos nosso foco, para uma de suas periferias, o bairro do Dirceu. Sigamos por um dos possíveis caminhos.

Seguindo para a região sudoeste de Teresina, o acesso mais fácil é chegar pela Avenida Joaquim Nelson, mas a via principal é a Avenida José Francisco de Almeida Neto, que é a cara do bairro Dirceu Arcoverde, o mais populoso de Teresina, com aproximadamente 37.443 habitantes (TERESINA, 2018). Conjunto habitacional do Itararé é o seu nome oficial, sua primeira etapa foi inaugurada em 1977 e o Itararé II em 1980, mas são conhecidos pela população como Dirceu I e II, e atualmente representam o Grande Dirceu. 
As casas iguais, da antiga Companhia de Habitação (Cohab), originalmente enfileiradas em quadras de chão batido criavam o cenário da precariedade ${ }^{1}$ : distantes $15 \mathrm{~km}$ do local de acesso ao transporte público, sem saneamento, sem luz e sem muita condição de existência.

Mas lá, com a passagem do tempo, com as idas e vindas daqueles cidadãos afastados do restante da cidade e a chegada de mais e mais moradores, a região constituiu-se como um território singular que contribuiu para a composição da identidade multifacetada daquela comunidade. Hoje, a cara do Dirceu é outra, mais dinâmica, com asfalto, repleta de lojas, bares, igrejas, templos, engarrafamentos, mercados, motos, clínicas, restaurantes, praças, escolas, farmácias, casas lotéricas, banquinhas de espetinho e arrumadinho, com seus diversos aromas e gente de toda sorte. A dinâmica permanece, a condição de periferia ainda está lá, refletida em preconceitos sociais e ausência de muitas das políticas públicas.

É nesse contexto que se encontra um dos três teatros da cidade, o Teatro João Paulo II, mas o público do bairro do Dirceu, em sua maioria, não é o mesmo que frequenta ou consome a programação cultural de exposições, recitais ou festivais de arte realizados no centro de Teresina, em sua maioria no Complexo Cultural do Teatro 4 de Setembro. Esses contrastes, ao tempo que representam uma realidade comum para quem habita a periferia, vêm a ser, por outro ângulo, um universo de potencialidades de naturezas múltiplas e transitórias com a criação de outros circuitos, ações e espaços alternativos.

As características desse contexto urbano e social propiciaram o surgimento de um espaço criativo, onde questões como a ausência, a carência e a distância, deram corpo às inquietações de um grupo de jovens artistas. O bairro Dirceu, um grande recorte de Teresina, testemunhou e experimentou entre 2006 e 2016, por meio do Núcleo do Dirceu, com a coordenação de Marcelo Evelin², um contínuo de ações culturais desenvolvidas a partir de suas práticas voltadas para a formação de jovens em performance e dança.

\footnotetext{
${ }^{1}$ Qualidade do que é precário; deficiência, fragilidade, insuficiência (PRECARIEDADE, 2019).

2 Marcelo Evelin é um artista natural de Teresina no Piauí; atua como coreógrafo, investigador e intérprete no cruzamento entre as áreas da dança contemporânea e do teatro físico. Reside entre a cidade de Teresina e a Europa. "É criador residente do Hetveem Theater em Amsterdam com sua Companhia Demolition Inc., ensina improvisação e composição na Escola Superior de Mímica de Amsterdam-Holanda, onde também cria projetos e orienta estudantes em processos criativos" (STILL MÓVIL, 2011). Implantou e coordenou por 10 anos o Núcleo do Dirceu conseguindo projetar os trabalhos do Núcleo e inserir o Piauí nos circuitos de festivais de arte contemporânea no país e em vários países do mundo. Desde 2016 está a frente do CAMPO, seu novo espaço de criação agregando artistas e colaboradores de forma horizontal e interdisciplinar.
} 
Em 2005, após alguns anos na Europa, o artista Marcelo Evelin regressa à sua cidade natal. Com um forte senso crítico ao sistema da dança estabelecido no Brasil, fixa-se numa cidade com poucos incentivos para a cultura e com uma pequena produção de dança (MATOS, 2015).

Como um artista contemporâneo reconhecido no Brasil e na Europa, Evelin poderia ter se estabelecido em uma das grandes capitais culturais do Brasil e trabalhado com outros renomados criadores da dança. Contrariamente a essa expectativa, retorna para sua cidade natal, incialmente para dirigir o Teatro Municipal João Paulo II, e permanece nessa função por três anos, até se indispor com a gestão da Fundação Cultural (MATOS, 2015).

Com a saída do Teatro, Marcelo Evelin e o grupo de 18 artistas $^{3}$ integrantes do Núcleo de Criação do Dirceu inauguram, em 2010, o Núcleo do Dirceu, iniciando uma nova etapa de produções e circulações dos trabalhos artísticos ali produzidos; enfrentando adversidades - não só econômicas, mas com a cultura local. Esse nativo-estrangeiro começa a mover essa terra árida, tão duramente assentada no campo da dança.

O Núcleo do Dirceu se configurou como uma plataforma de artistas e de produtores, com principal campo de interesse as linguagens das artes do corpo e artes performáticas. Formado por 18 artistas de várias linguagens, desenvolveu ações voltadas para a formação e criação em arte contemporânea por meio de pesquisas e projetos colaborativos.

No momento da instauração do Núcleo do Dirceu, em Teresina, não era usual a adoção de expressões como dança contemporânea ou performance. O Piauí ainda permanecia deslocado dos grandes eixos e festivais contemporâneos, com sua produção em dança voltada para grupos clássicos, modernos e folclóricos.

É diante desse cenário que este artigo visa cartografar um corpo singular/coletivo inserido num contexto árido, porém ávido. Assim, mapear as linhas que se cruzam ou escapam na tessitura de outros devires é um dos desafios na qual esta escrita se lança ao analisar questões presentes no projeto 1000 Casas, desenvolvido entre 2011 e 2012.

\footnotetext{
O 1000 Casas surgiu a partir de muitas questões próprias da existência e da permanência do Núcleo enquanto espaço de criação artística e sua relação com a comunidade. 1.000 Casas é um projeto de arte e intervenção domiciliar - aberto e em construção - embrenhado em um bairro periférico de uma cidade periférica do Nordeste do Brasil. Trata-se de uma sequência de ações performáticas que aconteceram - de visita ou 'assalto' - em mil casas da região do Grande Dirceu, em Teresina, durante os anos de 2011 e 2012. O projeto está focado na 'performatividade' do encontro e no diálogo com o outro, assim como na criação
}

${ }^{3}$ Fizeram parte da formação inicial do Núcleo do Dirceu: Alexandre Santos, Bid Lima, César Costa, Cipó Alvarenga, Eduardo Prazeres, Elieson Pacheco, Fábio Crazy da Silva, Fagner Christiê, Jamila Rocha, Janaína Lobo, Laila Caddah, Layane Holanda, Luciano Brandão, Luís Carlos Vale, Sergio Matos, Soraya Portela, Weyla Carvalho e Wilena Weronez. 
de um ambiente - simultaneamente fictício e real - que possibilite uma troca de subjetividade entre artista e morador, determinando assim a ação performática. Uma das intenções do projeto é abordar o lugar privado com um ato público. Nas ações desenvolvidas, o privado torna-se público e vice-versa, numa inversão que confunde também a noção de artista e espectador, e os sentidos do que seja arte e cotidiano. A esfera pública se estabelece de forma política pelo compartilhamento do comum. E a esfera privada, porque o acontecimento se dá na singularidade do indivíduo, em seu universo particular. 1.000 Casas é o traçado de uma série de atos públicos gerados no âmbito do privado - em torno de uma mesa e de uma panela de pressão que cozinha o feijão. A lógica do encontro e do compartilhamento com o outro se reproduz aqui numa nova situação criada entre o artista e um (outro) espectador. 1.000 Casas é uma instalação performática com caráter de acontecimento. Acontecimento como um estado de coisas encarnado, como o instante móvel de uma ação-pensamento, como algo que provoca e produz uma 'desacomodação' da experiência em cada um. 1.000 Casas é também um livro-percurso de imagens da subjetividade de um lugar e pessoas. É um livro que mesmo sendo sobre o Dirceu tem aberturas pra outros lugares porque nele existe a Vila Bagdá, a Rua Polônia (FUNARTE, 2013).

Desse modo, observam-se as relações estabelecidas no fazer arte, compreendendo nelas a precariedade presente entre os artistas do Núcleo e os moradores da comunidade, entre o contexto e a força motriz das suas composições e processos, gerados a partir das ocupações e afecções que esses corpos produzem no exercício de coexistir.

Aqui a abordagem de micropolítica é feita à luz de Deleuze e Guattari (2012), considerando, inicialmente, que tudo é político e que toda política é, ao mesmo tempo, macropolítica e micropolítica. Assim, essa relação interdependente, gera um campo de intensidades que não cessa de agitar os segmentos molares (macropolítica) e moleculares (micropolítica), sendo que no âmbito das micropolíticas as linhas de fuga potencializam na sociedade os espaços de rupturas e de outros modos de vida, de devires.

Por essa via, percebe-se que os trânsitos urgentes permeiam o "estar dentro e o estar fora" e pautaram o exercício dialógico e artístico estabelecido entre o Núcleo do Dirceu, o bairro Dirceu e a cidade de Teresina. Essas relações nos interessam pelos agenciamentos e micropolíticas produzidas no interstício dos acontecimentos performativos e nas reconfigurações culturais propostas em duas performances do 1000 Casas.

O projeto 1000 Casas foi organizado a partir de três linhas de trabalho: a abordagem, a performatividade e a documentalidade. Sua composição abrangeu vários tipos de ações, que poderiam acontecer de forma programada ou de surpresa, em espaços da comunidade. No que se refere à abordagem, inicialmente foi traçado pelos artistas um perfil das casas ou das pessoas que se queria atingir, cujas escolhas foram definidas por diferentes questões as quais se pretendia discutir na performance, tais como: casas sem muro, casas com textura na parede, casas de 
esquina, casas com pessoas acima de 70 anos, dentre outros parâmetros. A seleção feita por cada artista e a definição de seus critérios direcionava a forma de abordagem.

Aqui analisaremos apenas duas dessas ações: "Boneca" e "Empacotamento", dos artistas Jacob Alves ${ }^{4}$ e Soraya Portela ${ }^{5}$ respectivamente.

Ao analisar as características desse projeto, percebe-se que o Núcleo do Dirceu se constitui como um fluxo de forças que desloca o próprio contexto e propõe outros entendimentos por meio de suas práticas, na relação entre arte e vida, a partir de experiências, gestos e (des)encontros, promovendo mobilizações nos âmbitos sociais, culturais e políticos.

O Galpão do Dirceu, mais do que um espaço físico, é um espaço político de ajuntamento... Produz e recebe espetáculos, artistas em residência, processos de criação, batalhas de hiphop, encontros e palestras numa turbulência de instâncias auto-organizativas... O Galpão é um arranjo de acontecimentos interconectados... (EVELIN, 2014 apud GREINER; ESPÍRITO SANTO; SOBRAL, 2014, p. 74).

Diante desse contexto, passamos a analisar algumas das experiências geradas por esse coletivo de artistas independentes, percebendo as questões inerentes da própria permanência e do fazer arte em um bairro periférico.

\section{AFINAL, DE QUE PRECARIEDADE ESTAMOS FALANDO?}

Ao contextualizar o território para o qual o convidamos a percorrer, caracterizamos não só a localização do Núcleo, mas as condições às quais estão baseadas a sua existência. Embora o conceito de precariedade usado anteriormente denote uma relação direta com a escassez, artisticamente, como abordagem, a precariedade se propõe a ser potência de criação e relação entre obra-espectador, entre criador-mundo, visão esta relacionada às concepções de Lygia Clark e Hélio Oiticica (FIGUEIREDO, 1998), Eleonora Fabião (2011) e presente também na obra 1000 Casas, de Marcelo Evelin ${ }^{6}$.

O projeto 1000 Casas é abordado, pelos seus próprios fazedores, ora como projeto de intervenção, ora como um projeto de criação artística/instalação e/ou uma performance. Para esta análise será adotada a ideia do ato performativo e, apesar de Peggy Phelan (1997) nos alertar que a

\footnotetext{
${ }^{4}$ Jacob Alves é atualmente diretor do Junta Festival Internacional de Dança e ex-integrante do coletivo Núcleo do Dirceu. Foi artista residente/diretor e curador do espaço Balde e investiga arte tecnologia/tecnologia precária e biogambiarra.

5 Soraya Portela integrou o Núcleo do Dirceu e é artista, educadora e pesquisadora. Atua na área da dança, performance e gestão cultural. Estuda e pesquisa práticas artísticas que pensam o corpo na infância e na velhice.

${ }^{6}$ Esse termo também é explorado por autores como Vilar (2017), dentre outros. Neste texto optamos pelos autores acima citados, cujas abordagens criam nexos com o conceito de micropolítica de Deleuze e Guattari.
} 
performance se dá no presente, ou seja, no seu acontecimento, anunciando assim a impossibilidade dos registros da performance, utilizamos para a análise deste artigo os registros audiovisuais/obras de arte $^{7}$ referentes a duas performances do 1000 Casas e as enunciações feitas por seus participantes - artistas e moradores -, o que implica um terceiro olhar sobre o ato da performance, já ausente, a partir dos rastros presentes no vídeo, nas fotos e nas ressignificações postas nesta escrita.

Eleonora Fabião, em seu artigo "Performance e Precariedade" (2011), declara que encontrou pela primeira vez o termo precariedade nos escritos de Lygia Clark, quando a artista, em seus experimentos estéticos, retira o foco do objeto artístico e da relação tradicional entre artista e espectador e invoca a necessidade de criarmos outros modos de produção e de existência, para que se possa "[...] aprender a viver sobre as bases da precariedade" (CLARK, 1997 apud FABIÃO, 2011, p. 63-64).

Ao propor outra organização e forma de relacionamento entre o artista, o espectador, o ambiente e a obra, Lígia Clark coloca o artista enquanto propositor de experiências a serem vividas pelo espectador, enquanto este manipula a obra, relaciona-se com ela de diversas formas, encontrando outras possibilidades que expandem a experiência e geram novos sentidos à própria obra.

A precariedade desenvolvida enquanto conceito/ação nas obras de Lygia Clark torna-se um elemento na investigação para outras formas de se relacionar com o corpo, o objeto artístico, a (co)existência e a aprendizagem. Fabião (2011), por sua vez, propõe precariedade na performance como base conceitual e estratégia dramatúrgica para criar performances, já que os:

Performers são poetas que investigam, criam e disseminam precários: precariedade do sentido (que deixa de ser pré-estabelecido e fixado para ser condicional, mutante, performativo), precariedade do capital (cuja supremacia é desbancada e a pobreza exposta), a precariedade do corpo (que longe de ser percebida como deficiência, é atualizada como potência) e a precariedade da arte (que se volta para o ato e para o corpo) (FABIÃO, 2011, p. 65).

A precariedade no ato performativo, ao contrário de ser compreendida na relação entre performance e falta de recurso financeiro, traz em si uma dimensão política, social, econômica e conceitual que se revela como potência, levando à recriação, à desmecanização de hábitos

\footnotetext{
${ }^{7}$ No release sobre esse projeto, o Núcleo do Dirceu considera esses registros, com conteúdos multimídia, outra obra de arte (NUCLEO DO DIRCEU, [2011]).
} 
comportamentais e culturais, através da dinamização do corpo, potencializando sua presença no mundo, como uma forma de pertencimento crítico, propositivo e intencional.

Identificamos que esses questionamentos e posicionamento crítico e político, a partir da precariedade, presentes nas práticas artísticas do Núcleo do Dirceu, bem como nos modos de subjetivação, possibilitam o alargamento dos conceitos de partilha e de experiência utilizados por esse coletivo. Segundo Marcelo Evelin, o projeto 1000 Casas partiu de muitas questões próprias da existência e permanência do Núcleo, na qual a metáfora da CASA se constituía e se transformava a partir de provocações:

O Projeto 1000 CASAS surgiu a partir de mais de uma questão: o que as pessoas estão fazendo em casa enquanto um espetáculo acontece? Como um espetáculo poderia vir acontecer nessas CASAS como inversão da situação público x privado? Como poderíamos testar um tipo de performatividade que embaralhasse os papéis de artista e espectador, $\mathrm{e}$ que viesse a operar na situação 'estar em casa' como parte determinante dessa performatividade? Foi um tiro no escuro, mas com a determinação de um tiro certeiro (NÚCLEO DO DIRCEU, 2012, p. 238).

Esses questionamentos sobre o sentido da "casa", as discussões feitas ao redor da mesa para as escolhas sobre as formas de abordagens, seus processos e os potenciais alvos, refletem modos de articulação e compartilhamento do comum no Núcleo do Dirceu, o que nos permite relacioná-lo também ao conceito da "partilha do sensível", o qual desvela suas maneiras de ser, modos de estar no mundo e de fazer arte. Para Ranciére (2009, p. 15):

Denomino partilha do sensível o sistema de evidências sensíveis que revela, ao mesmo tempo, a existência de um comum e dos recortes que nele definem lugares e partes respectivas. Uma partilha do sensível fixa, portanto, ao mesmo tempo, um comum partilhado e partes exclusivas. Essa repartição das partes e dos lugares se funda numa partilha de espaços, tempos e tipos de atividade que determina propriamente a maneira como um comum se presta à participação e como uns e outras tomam parte nessa partilha.

Como uma forma de prover a manutenção do espaço e iniciar um novo projeto artístico para o Núcleo do Dirceu, foi criado o projeto 1000 Casas, para ser realizado num período de dois anos (2011-2012). Segundo Matos (2015, p. 11),

[...] com uma proposta de criação colaborativa e fomentando outros modos de se relacionar com a comunidade local, o Projeto 1000 Casas se baseia em ações performativas e intervenções em domicílios, nos quais os artistas interagem com os moradores, registram as ações, bem como são filmados pelos moradores de cada casa. Todas as ações partem de três diferentes possibilidades: escolhas (com negociações realizadas previamente para a entrada na casa); assalto (surpresa) e arrastão (mais de uma casa é incorporada). Não é mera coincidência o uso dessas nomenclaturas. Muitas pessoas da classe média brasileira, numa análise crua, consideram que os assaltos e arrastões que acontecem em nossas cidades são executados pelos 'marginais' da periferia (aqui se toma a parte pelo todo). 
Assim, borrando essas fronteiras entre sujeitos, tempos e espaços, uma corresponsabilidade se estabelecia a cada ação e intervenção realizada na casa de um dos moradores, feitas de "visita" ou de "assalto", possibilitando ao artista e ao público a cocriação de sentidos daquilo que a arte faz ou daquilo que a faz ser arte.

$\mathrm{CASAS}^{8}$ como metáfora, como pesquisa, como sustento, como lugar, como território a ser explorado artisticamente no encontro e no diálogo como o outro, na emergência das situações, nos desvios, como um lugar-corpo a ser percebido lentamente, na invenção de abordagens e na criação de outros nexos.

Em uma das intervenções de 1000 Casas, denominada "Boneca" (1000..., 2011), um dos performers, Jacob Alves, realiza a ação da "escolha" em um salão de beleza do bairro. Ele entrega a sua filmadora para a dona do salão, para ela escolher a forma de registrar essa ação. Em seguida,

O performer abre sua mochila e começa a tirar seus objetos cênicos/pessoais. A moradora pergunta o que ele faz, enquanto pinta o rosto simulando uma barba. Ela oferece um batom rosinha, caso ele prefira uma cor. Quando ele começa a soprar sua boneca inflável, a senhora pergunta se é um companheiro ou companheira e o performer desvela uma opção pelo sexo feminino. Há uma música "brega" ao fundo, a qual fala de uma relação rompida. Enquanto infla a boneca, o cachorro late com os movimentos desse objeto. A dona da casa dá gargalhadas e tenta expulsar o cachorro. O dançarino deita-se sobre o sofá, completamente vestido, e coloca a boneca sobre seu corpo. Não há nenhuma simulação de movimentos sexuais. Ele apenas começa a apertar lentamente a boneca e esta começa a murchar... a boneca, enfim, repousa sobre o corpo do dançarino. Totó, o cachorro, como é chamado por sua dona, toma a boneca e arrasta-a pelo quintal e, pela primeira vez, aparece um rosto impresso na boneca inflável, que remete à imagem da Xuxa, a apresentadora de TV. Outro cachorro participa dessa cena (MATOS, 2015, p. 11).

Em outra performance denominada "Empacotamento" (CINETEATRO, 2012), realizada como uma ação de "visita" na casa de um idoso, o Sr. Joaquim Antônio Neto, a performer Soraya Portela se embrulha em uma longa folha de papel kraft para abordar o tema da morte, tentando banalizá-la para valorizar a vida e as (im)possibilidades diante da realidade da finitude da vida. Nesse ato de embrulhar o próprio corpo, o diálogo da performer com o morador é embalado a partir das memórias do Sr. Joaquim, provocado a falar de seu passado/presente; pensando em como nos tornamos um pacote de lembranças. O início dessa composição performativa é marcado pela observação desconfiada do Sr. Joaquim, ao olhar aquela mulher, sozinha, se embalando. Depois, quando sua ajuda é solicitada, ele aos poucos vai se tornando parte da obra, não só pela ajuda, mas pela partilha das histórias de vida que ele enuncia ao longo da performance. Joaquim, um agricultor de 75 anos, mora sozinho numa casa pequena; foi casado por 28 anos, é pai de sete

\footnotetext{
8 Jogo imagético da palavra proposto pelas autoras.
} 
filhos - três mortos e quatro vivos - que pouco o visitam. Nunca foi assistir a um "show de teatro", mas gosta de dançar forró e acredita que tomar café com whisky é muito bom para a memória. Ele nunca estudou, porém um dos seus filhos estudou e se dedicou a política, mas Joaquim continua lá, quase esquecido, no Dirceu.

Portela (2012) afirma que sua performance se dá no próprio encontro, na abordagem e em todo o movimento (ou imobilidade) próprio da casa; a performance ocorre como um modo de estar junto, assumindo os riscos na aproximação e de se colocar no lugar do outro. Ao mesmo tempo, segundo a artista, ocupar esse lugar do outro não visa apenas o compartilhamento do espaço, mas um deslocamento para/com outro universo de particularidades, costumes e receios. Nesta performance/“visita", articulada por Soraya Portela com "seu" Joaquim, a precariedade - de sentidos, do corpo, da arte e do capital, tal como aborda Fabião - se faz presente a partir das aberturas criadas a relação se estabelecer, recriando a obra a cada ato performativo, tecendo nexos com o que se tem no momento, com quem está presente e com o espaço onde ela é realizada; isso provoca, em cada casa visitada, outras reflexões sobre o corpo, a vida, a morte e o tempo.

As duas obras apresentadas discutem em sua composição a estética da precariedade, por meio de uma condição de instabilidade, de relatividade e de indefinição de uma forma, em favor da permanente renovação de si, do meio e da arte (FABIÃO, 2011). Assim, por meio do seu modo de fazer arte, essas obras desvelam a potência do ato performativo, a qual está imbricada nas escolhas de abordagens e temas, na forma de ocorrência das ações e nas relações tecidas com os participantes.

Ao mesmo tempo, a condição de instabilidade a qual os artistas se colocam ao performar em um ambiente desconhecido, possibilita a ocorrência de um ato performativo o qual propõe uma experiência artística que se desloca para o espaço privado da casa. Essa ação distende visões estagnadas sobre o lócus do fazer artístico bem como sobre as relações entre público/privado, artista/espectador, borrando essas oposições através da experiência, a qual se torna um momento único e compartilhado sem um propositor único, traçando, assim, outras linhas possíveis.

De tal modo, a partir dessas ações de aproximação e/ou invasão a proposição do Núcleo do Dirceu foca na performatividade de cada encontro. Em cada um deles, os artistas recolheram, em caixas, registros dessas ações - vídeos, fotos, diários, desenhos, aromas e sabores... - e essas pistas passam a ser potenciais materiais impulsores de novos processos criativos. As caixas 
colecionam desejos. Elas viraram, posteriormente, a instalação ${ }^{9}$ performática 1000 Casas com as caixas abertas e entrecruzadas com outros materiais, seus conteúdos geraram um livro-percurso (NÚCLEO DO DIRCEU, 2012).

No bairro onde ficava localizada sua sede, o Núcleo gozava de pertencimento e acolhimento. Fizeram parte daquela paisagem e literalmente espalharam a arte, indo além das 1000 casas. Pertenceram àquele e a outros mundos, sem a certeza de suas próprias permanências. Enquanto criadores, a partir de suas precariedades, geraram novas estratégias de sobrevivência para se manterem no sertão, criaram outras formas de (co)existir e se relacionar com a comunidade.

O longo processo de dois anos do projeto 1000 casas possibilitou o reconhecimento da performatividade do encontro, a qual foi cunhada por Evelin (2012) como uma "terceira performatividade", que, segundo esse artista, emergiu com a complexificação das abordagens:

Falávamos de uma 'terceira performatividade' como algo a ser buscado entre uma forma de atuação mais estruturada e um tipo de visita espontânea. Um lugar-margem para essas performances que se dariam inevitavelmente entre o que é público e o que é privado, e quase sem distinção entre o artista e o espectador, e sim como possibilidade de inversão espontânea desses papéis durante a ação performática [...]. A terceira performatividade passou a ser a válvula de escape da situação desconhecida a que nos propúnhamos enfrentar nessas CASAS. Seguíamos com as discussões e ideias vinham aos montes, mas pareciam não ecoar no que conhecíamos como modo de pensar e fazer. As abordagens se complexificavam à medida que nos dávamos conta de que essa era - de toda maneira e felizmente - a performatividade do encontro (NÚCLEO DO DIRCEU, 2012, p. 238).

Na experiência de Soraia Portela, uma das 14 artistas participantes do Projeto, a complexidade do encontro era a própria performance:

[...] A permissão de performar é nesse caso quase como a vontade de gritar, de vomitar, é construir a partir do que você tem, de provar do risco, não saber o que encontrar e ver quanto e quão poroso você é ou se permite ser, de ficcionar a sua realidade e a do outro. Performar só é possível no momento em que não há algo a ser revelado, ou quando me dá, como artista, propriedade de dizer para as pessoas o que não tenho coragem de dizer, como eu ando pensando as coisas do mundo (NÚCLEO DO DIRCEU, 2012, p. 251).

O encontro, algo da ordem do inusitado, também é entendido como o elemento fundamental para a prática cartográfica. Segundo Silva (2012, p. 243), nos deslocando, podemos potencializar outras ações, ou seja,

Quando se quebra essa barreira Artista/Espectador é que a arte ganha intensidade na sua expressão e realmente age. Para o público: transforma o estranho/arte em uma nova forma

\footnotetext{
${ }^{9}$ Estreou no Especial de Dança do Itaú Cultural - Dança/SP (2012). 
de percepção cotidiana, para o artista: ganha um amigo, um ouvinte, um olhar, uma nova forma de agir em seus conceitos de fazer/agir/criar.

O encontro e a performance, como relacionam Marcelo Evelin e Soraya Portela, potencializam o surgimento dessa "terceira performatividade", um agenciamento coletivo de forças que possibilita uma coprodução, em que "[...] há a transformação da experiência em conhecimento e de conhecimento em experiência, numa circularidade aberta ao tempo que passa" (BARROS; KASTRUP, 2015, p. 70).

Esse movimento permanente que se dá na performatividade, a partir do potencial do precário, é um agenciamento coletivo o qual revela um plano de composição resultante de afetações, deslocamentos e reconfigurações das micropolíticas do desejo, tornando possíveis outros modos de existir, artística e politicamente. Conforme cita Fabião (2011, p. 77),

A performance é a arte do desmanche: desmanchar estratos através do corpo politizado e para a politização do corpo. Desnaturalizar o corpo da arte para a criação de um mundo em experimentação política", onde a experiência da precariedade possibilita o desmanche de estratos e a recriação de um mundo em experiência política.

O projeto 1000 Casas, através das performances dos seus integrantes, "desmancha" esse lugar confortável da arte, assumindo os riscos do inesperado, tornando-se parte do ambiente cotidiano e encarregando-se de engendrar as questões próprias de situações experimentadas.

\section{PROVISÓRIAS CONCLUSÕES: DIRCEU ～NÚCLEO ～ 1000 CASAS $^{10}$}

O Núcleo do Dirceu, que já contém o bairro dentro do próprio nome, é um espaço de arte ocupado por artistas que, em seu projeto de intervenção/ criação/performance, ocuparam casas do bairro, casas estas que se abriram para esse compartilhamento e depois receberam o retorno dos artistas, para os moradores/artistas compartilharem uma outra produção artística, o registro do próprio ato performativo realizado. Os trânsitos entre esses espaços de criação estabeleceram um fluxo de relações e criaram potentes espaços de partilha.

O compartilhamento do comum, na perspectiva rancieriana, nos ajuda a perceber os aspectos estéticos das interações e experiências dos sujeitos envolvidos num determinado contexto, considerando questões e tensões do fazer político, nas relações entre arte e vida, entre público e privado, o que possibilita a geração de outros conhecimentos, de outras visões de arte.

${ }^{10} \mathrm{n}=$ Intersecção. Explora-se aqui a ideia matemática criando o elemento do entre, de um espaço comum. 
A performatividade de ocupar/estar em casa, nos modos de criar e partilhar a autoria de uma obra, possibilita múltiplas e potentes intercessões que tencionam não só o espaço comum, mas também reverberam em outros atravessamentos apresentados no decorrer do próprio projeto e nas relações de pertencimento do Núcleo com a comunidade.

Nos processos de criação do 1000 Casas, o foco na singularidade do corpo-em-experiência e a crítica às representações, dentre outros aspectos, apresentam-se não como uma fórmula pronta para a criação, mas como proposições cuja composição performativa se dá no momento de sua realização.

"Desmanchar" através da precariedade e da performatividade do encontro tornou-se um exercício diário praticado por todos os envolvidos no projeto 1000 Casas, por meio dos seus processos de criação e modos de produção; afetando e deixando-se afetar, dando e recebendo, não por vias lineares e arborescentes, mas por vias de múltiplas mãos, repletas de possibilidades e distintas perspectivas.

As dinâmicas vividas pelo Dirceu, da sua criação às inúmeras metamorfoses ocorridas nesse bairro, se misturam com os movimentos realizados pelo Núcleo do Dirceu, entrelaçando-se num fluxo de continuidades e rupturas que reverberam no borramento de fronteiras, tornando-o uma referência da dança no Piauí, cuja produção artística proporcionou novos encontros, com outros contextos e pessoas, dentro e fora do Brasil.

Esse exercício ativo de operar sobre o mundo, ao mesmo tempo em que se revela como método de trabalho/pesquisa artística, como posicionamento estético e político, é igualmente potente no processo cartográfico adotado para esta pesquisa e na escrita deste artigo.

Assim, buscou-se apresentar rastros de uma prática artística singular, tecida num estado imersivo, como experiência da criação de um corpo implicado com o outro, com o espaço, com a comunidade. As Casas se multiplicam e se (re)compõem; tornam-se outras CASAS.

\section{REFERÊNCIAS}

1000 Casas Bonecas. [Teresina: s.n.], 2011. 1 vídeo (5 min.). Publicado pelo canal Jacob Alves. Disponível em: https://www.youtube.com/watch?v=gjByg3X6sm0. Acesso em: 05 nov. 2019.

BARROS, Laura Pozzana; KASTRUP, Virgínia. Cartografar é acompanhar processos. In: PASSOS, Eduardo; KASTRUP, Virgína; ESCOSSIA, Liliana (org.). Pistas do método da cartografia: pesquisaintervenção e produção de subjetividade. Porto Alegre: Sulina, 2015. 
CINETEATRO: Núcleo do Dirceu. [S.I.: s.n.], 2012. 1 vídeo (84 min.). Publicado pelo canal festivalpanorama. Disponível em: https://www.youtube.com/watch?v=JZ5BUU060H8. Acesso em: 05 nov. 2019.

DELEUZE, Gilles; GUATTARI, Félix. Mil Platôs: capitalismo e esquizofrenia. 2. ed. São Paulo: Ed. 34, 2012. v. 3.

EVELIN, Marcelo. Marcelo Evelin. In: NÚCLEO DO DIRCEU. 1000 CASAS. Teresina: Núcleo do Dirceu, 2012. p. 240.

FABIÃO, Eleonora. Performance e precariedade. In: OLIVEIRA JÚNIOR, Antônio Wellington de. A performance ensaiada: ensaios sobre a performance contemporânea. Fortaleza: Expressão Gráfica e Editora, 2011.

FIGUEIREDO, Luciano (org.). Cartas 1964-1974: Lygia Clark \& Hélio Oiticica. 2. ed. Rio de Janeiro, Editora UFRJ, 1998.

FUNARTE. 1000 Casas: FID na Funarte MG. Rio de Janeiro: Funarte, 2013. Disponível em: http://www.funarte.gov.br/evento/1-000-casas-fid-na-funarte-mg/. Acesso em: 20 set. 2019.

GREINER, Christine; ESPÍRITO SANTO, Cristina; SOBRAL, Sônia (org.). Cartografia Rumos Itaú Cultural dança: formação e criação. São Paulo: Itaú Cultural, 2014.

IBGE. Coordenação de População e Indicadores Sociais. Síntese de indicadores sociais: uma análise das condições de vida da população brasileira: 2017. Rio de Janeiro: IBGE, 2017.

MATOS, Lúcia. Danza e diferencia. In: ENCUENTRO ANDANZAS, 2015, Lima. Conferência [...]. Lima: Pontificia Universidad Catolica del Peru, 2015. Não publicado.

NÚCLEO DO DIRCEU. 1000 CASAS. Teresina: Núcleo do Dirceu, 2012.

NÚCLEO DO DIRCEU. 1000 CASAS. Direção artística: Marcelo Evelin. Teresina, [2011]. Disponível em: https://www.demolitionincorporada.com/1000casas. Acesso em: 05 nov. 2019.

PHELAN, Peggy. A ontologia da performance: representação sem reprodução. Revista de Comunicação e Linguagens, Lisboa, n. 24, p. 171-191, 1997.

PORTELA, Soraya. Soraya Portela. In: NÚCLEO DO DIRCEU. 1000 CASAS. Teresina: Núcleo do Dirceu, 2012. p. 253.

PRECARIEDADE. In: DICIONÁRIO online do Michaelis. São Paulo: Melhoramentos, 2019. Disponível em: https://michaelis.uol.com.br/moderno-portugues/busca/portugues-brasileiro/precariedade/. Acesso em: 25 fev. 2019.

RANCIÈRE, Jacques. A partilha do sensível: estética e política. São Paulo: Editora 34, 2009. 
SILVA, Cleyde. Cleyde Silva. In: NÚCLEO DO DIRCEU. 1000 CASAS. Teresina: Núcleo do Dirceu, 2012. p. 240.

STILL MÓVIL. Marcelo Evelin. [S.I]: Red Suramericana de Danza, [2011]. Disponível em: http://www.stillmovil.com/artistas/marcelo-evelyn?lang=pt. Acesso em: 17 nov. 2019.

TERESINA (PI). Secretaria Municipal de Planejamento e Coordenação. Perfil dos Bairros: Dirceu. Teresina, 2018. Disponível em: http://semplan.teresina.pi.gov.br/wpcontent/uploads/sites/39/2018/08/ITARAR\%C3\%89-2018.pdf. Acesso em: 05 nov. 2019.

VILAR, Gerard. Arte Contemporânea e Precariedade. Revista-Valise, Porto Alegre, v. 7, n. 13, p. 137-153, set. 2017. Disponível em:

https://seer.ufrgs.br/RevistaValise/article/viewFile/76553/43758. Acesso em: 05 nov. 2019. 